
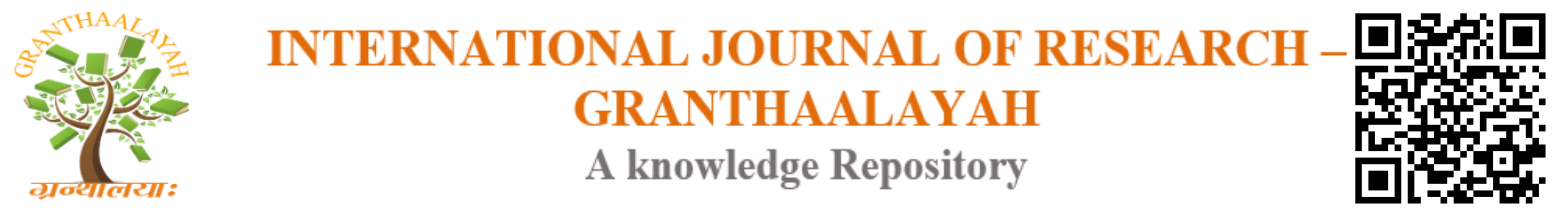

Management

\title{
EMPLOYEE FREEDOM: TILL WHAT EXTENT?
}

\author{
Dr. Sihem Bouguila *1 \\ ${ }^{* 1}$ Assistant Professor, Department of Business Administration, ISG TUNISIA
}

\begin{abstract}
In this study we aimed to assess the perceptions of employees regarding the different autonomy initiatives undertaken by managers to satisfy their employees and let them be more motivated in order to reach the organizational goals effectively and efficiently. We employed an exploratory study through a survey questionnaire addressed to 50 employees working in top five companies in the Kingdom of Bahrain. Our main finding show that the level of the autonomy in the sample companies is perceived as to be at moderated level especially concerning the goals or the strategies of the work since the majority of our companies are operating in banking sector. Nonetheless it seems that the autonomy provides a sense of self-determination for these employees even when freedom leeway and choice are trivial or illusory. Furthermore, it is very interesting to reveal that autonomy is one of the essential elements in building true employee engagement.
\end{abstract}

Keywords: Autonomy Initiatives; Freedom; Leeway; Employees Perceptions; Leadership Control; Engagement.

Cite This Article: Dr. Sihem Bouguila. (2019). "EMPLOYEE FREEDOM: TILL WHAT EXTENT?." International Journal of Research - Granthaalayah, 7(3), 282-301. https://doi.org/10.29121/granthaalayah.v7.i3.2019.974.

\section{Introduction}

Without employee organization cannot get the job done since he is the dynamo of the production process and his participation is crucial for the goals achievement process as he is one of the most important inputs to reach the organizations goals Joo et al (2010).

Several studies have examined the relationship between employees' satisfaction and their degree of commitment and performance, (Jiang et al, 2011; Fu et al, 2014; Falkenburg et al 2007). Nonetheless, satisfaction include many items: good wages, good work conditions, good training, good incentives, career development, reinforcement, rewards, holidays, good treatment, flexible time, participating in the goals achievements, participating in making decisions so getting leeway of freedom, feeling of responsibility. Many believe that the most important element of the individual satisfaction is how to provide the exact leeway of freedom to the employee in his workplace to feel responsible and more motivated to reach the organization goals, (Al-Tit et al 2015; Greasley et al ,2005). 
The question revealed in this study is to determine what we mean by giving freedom and what type of freedom/autonomy should be given: time, tasks, places....

In fact, due to the stress many employees are less motivated and not satisfied about the work conditions especially whenever their managers are shouting on them if they were doing mistakes and they exercise a strict control over their work and over their timing. They feel controlled all the time which can kill their initiatives and perceive their work as punishment so they work always under the fear however employees can perceive positively the managers that are ready to give them a leeway of freedom in their schedule, methods and places where to work, (Kleanthis et al , 2014). In this research we aim to show the importance of such flexible leadership which recognize the freedom of the employees in their work. Per consequence we intend to assess the perceptions of employees regarding the different autonomy initiatives undertaken by these managers to satisfy their employees and let them be more motivated to innovate and take the initiatives by themselves to reach the organizational goals.

So, the fundamental research question is how employees perceives the autonomy initiatives in the kingdom of Bahrain.

Thus, we intend in this work to clarify the nature, types and the degree of freedom that should be given in order to motivate the employees and increase their positive perceptions towards their work.

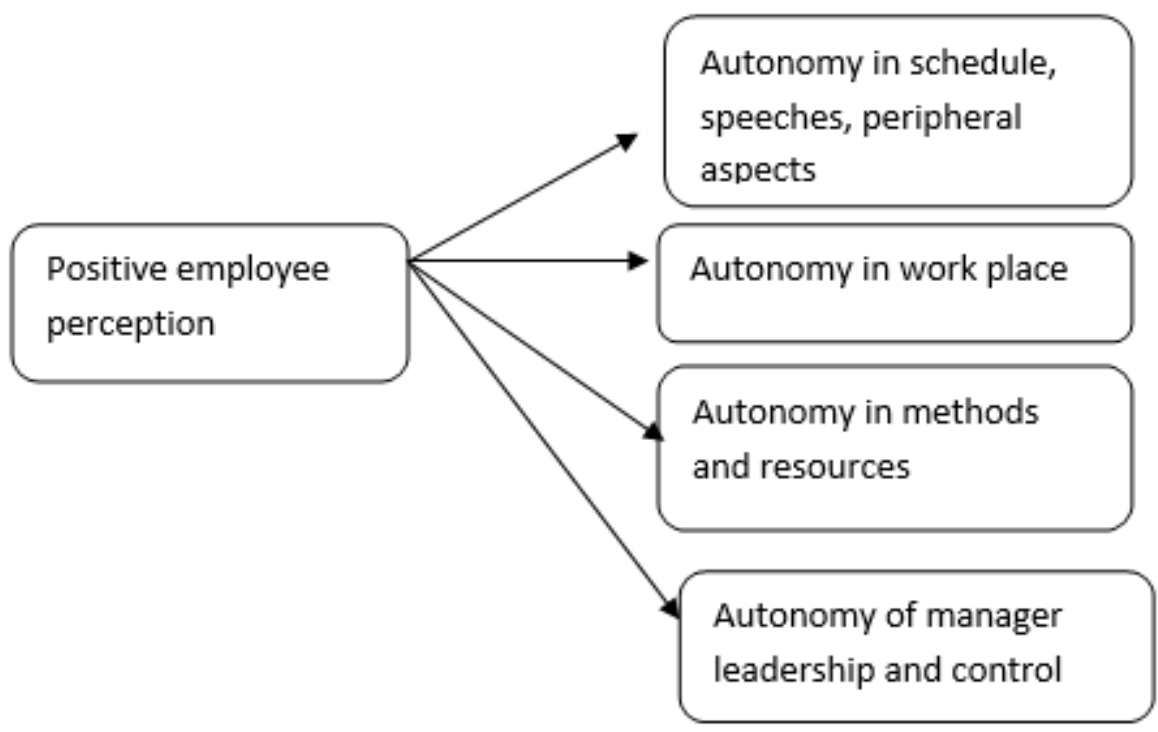

\subsection{Hypothesis of The Study}

Whenever the employees are allowed to work what, where and when they want can have a significant effect on their perceptions toward their work and per consequences on their productivity and on the organization performance. Thus, employees that had less control on tasks, schedule, presence, resources were more motivated. 


\section{Review of the Literature}

First of all, we have to distinguish between what is autonomy and also what autonomy is not. In fact, autonomy is the power to shape the work environment in ways that allow employee to perform at his best. However, the autonomy does not mean working in isolation and it does not give a person the right to work without supervision or collaborators. And it is not whatever employee want and whenever he likes, in the organization with high levels of autonomy. The manager defines the boundaries of the employee' control and decision-making power and creates the environment in which the employee can choose how autonomous he or she wishes to be, Whaley et al,1994). Especially it does not mean working without a net. In a well-run organizations, autonomous employees receive strong clear guidance from supervisors, established procedures, manuals and so on (Li Tao et al,1970). It is only dysfunctional organizations that employees are left to figure out their jobs with little or no input from management. That is not autonomy that is lack of leadership. So, it is very important to distinguish between these two concepts. Therefore, in autonomous organization the concern is focused on what gets dons with less concern for how it gets done. Hence, the bottom-line benefit to both employees and organizations is that workers who are free to make more choices are happier, more committed to their jobs productive and less likely to leave (Steiner, 2017). According to 2009 Forrester report 'by 2016, $43 \%$ of the U.S. workforce - 63 million people - are expected to work from home; 34 million people already do. This trend is driven by a number of factors, including professionals' desire to have control over their day-today work life'. 'Companies that officially allow employees to work distantly at least three times per month were more likely to report revenue growth of $10 \%$ or more within the last year, compared to firms without such policies. And some companies, like videogame maker Valve, attribute much of their commercial success to their open workflows, i.e. arrangements where employees get to choose which projects they work on and which roles they play on those projects. Valve also cites this level of autonomy as one of its primary competitive advantages in recruiting and retention....

Here are a few examples of companies that prioritize a strong culture of self-care and freedom: Many large companies track and report the efficiencies and benefits they gain from remote work policies. For example, $\mathrm{Cisco}^{2}$ estimates that it saves 277dollars million each year from productivity gains related to telecommuting employees.

Another study released at the World Economic Forum in Davos found in a deep study that companies in which employees displayed "high levels of freedom" in their relationships were 1020 times more likely to outperform companies with low freedom scores.

At the gerson Lehrman groups global HQ office in New York, employees don't have assigned team work areas, but rather work in "neighborhoods", flexible working spaces that have various amenities (conference rooms and tables, phone booths, even overnight lockers) and are free to pick up and relocate to another neighborhood when they see fit. They also work under highly autonomous workflows, especially their engineers. Engineers choose their own projects, engaging

\footnotetext{
${ }^{1}$ By Ted Schadler, Matthew Brown, Sara Burnes 'US Telecommuting Forecast', 2009

${ }^{2}$ Source: https://newsroom.cisco.com/press-release-content?type=webcontent\&articleId=5000107
} 
with business operators across the company directly, no project management, no product management.

At Rework, all of employees have four weeks of paid vacation each year, as well as four weeks of remote work eligibility and unlimited sick days. they've had employees do extended work trips from Colombia, Brazil, Uganda, and cities across the U.S. they adopted these policies after months of research and observing similar policies at organizations, such as Reasoning Mind, a Houstonbased educational software nonprofit that also encourages its employees to take 4-week remote work stints each year.

The employees of Zappos company are free to express themselves. Whether it is making the decision to send flowers $t$ a customer without asking for permission, or decorating their workpace like a Mardi Gras float, employees have free region. In fact in 2013, CEO tony Hsieh announced that the company was going to restructure into a holacracy, a corporate structure that removes the typical hiearchy found in most organizations. Thus authority and decision making power reside within self-organizing teams. So at Zapoos, employees clearly have a high level of freedom.

Google is another example that is at the principal of creating an environment in which people have a lot of freedom, for instance, employees are free to use 205 of their time to work on any google related project they want, some of google's best ideas, such as gmail, came out of this' free'time . Another software company at the forefront of employee freedom I s37 singals. They make a popular project management tool called base camp. The developer in 37 signala have the freedom to work the hours they want to work. If employees hit stride at 3 am then they are free to work overnight. As long as the work is getting done they can work at anytime and anywhere they like. It is similar to the concept of the results only work environment ROWE popularized by its adoption by best buy corporate.

"Participating in the ROWE initiative directly increases employees' health-related behaviors of sleep and exercise, as well as the likelihood that employees will not go to the workplace when sick and will see a doctor when sick."

The 300 people involved in Best Buy's flex program got on average 30 more minutes of sleep every night, and improved their health over a six-month period. They also had less "work-family conflict," which arises when there's a work "spillover" effect. Those who didn't have a flex schedule were at a higher risk for "unhealthy eating habits, obesity, elevated cholesterol levels, and hypertension." It's also worth noting that $41 \%$ of the participants were working more than 50 hours per week, had an average age of 32 during the time of the study, and $48 \%$ were women. Most were married.

Employees at Nation Swell, a new media startup focused on telling the stories of American citizens, business owners, and ventures changing the fabric of country for the better, work together in their New York City office on Mondays, but are free to roam the city and work in coffee shops or wherever they please for the rest of each week.

Firms like 37Signals, Mozilla, UpWorthy, Universal Mind, StackExchange, GitHub, and Treehouse are known for having fully or largely distributed teams from day one, and they use that to their advantage in recruiting the best talent wherever they live. 
These policies are examples of results-oriented management thinking. That is to say, policies shaped based on outcomes, not process. If someone can do their job and do it well while absent from the office, more power to them.

\subsection{Types of Leeway Freedom}

\subsubsection{Freedom in the Time}

Giving employees the freedom to set their own schedule and level of responsibility can encourage them to treat each job as an opportunity to make a great impression and to improve their service regarding the customer. In fact, behavior of people generally is different from one to another. Some find that it is better to do their work in the early morning since they feel more energetic and enthusiastic so they have more concentration on their tasks (Won-Moo et al,2018). However, others prefer to work on the weekends or in the evening. Thus, having the freedom to choose the suitable time when we can do our work is exceedingly empowering. Nonetheless, most of managers still not relinquishing control over employees' schedules Hardiyana et al (2015). They are still following strict control in the employees schedule from 9 to 5. Also, corporate policies and practices offering employees greater schedule control that is the ability to decide when and where they do their jobs may be especially important for the health behavior and wellbeing of contemporary employees, given the increasing time pressures, time speed-ups, and time conflicts most are experiencing (Steiner,2017). Flexible schedules won't work in every office environment, and there's certainly value to face time. And of course, a fully trust should be attributed to the employee who is letting to have work flexible hours. Furthermore, some managers are putting camera to see the employees working. This way of control not only makes the employees feel not comfortable in their workplace but especially it reflects that the managers are not hiring the right people to do the work or that those managers are autocratic by nature. However, it is obviously that whenever we let the employees to control their work schedules will lead to more autonomy and responsibility but still the question to which extent give the control margin to the employees (Steiner,2017).

This is the dilemma that should be resolved by the direct manager who can examine the situation and take the right control on his employees that is why we believe that the best manager should be contextual and situational.

\subsubsection{Freedom of Speech in the Workplace}

Many employees are sharing information about pay benefits, safety, and work related issues especially during the break time or on the social media. A real example of work place freedom of speech

Situation: A group of employees who worked for a retail store in a touristy area of San Francisco were concerned about their safety due to their store's closing an hour later than other nearby stores. After unsuccessful discussions with the manager and later, the owner, the employees posted their frustrations on Facebook. An employee who saw the posts showed them to the owner, and subsequently, the other three employees were fired. 
Ruling: The National Labor Relations Board reviewed the Facebook posts and determined they were acceptable. The employees were discussing the store's closing earlier based on legitimate safety concerns, so the posts were considered protected under the NLRA. It was determined that the employer committed an unfair labor practice by firing the employees.

However, there are limits to what the employees should speak about or not to speak at all. It's important, too, that guidelines regarding freedom of expression be carefully crafted and uniformly enforced so all employees are treated equally (Jiang et al, 2011).

\subsubsection{Freedom in Behavior}

Managers also should be diligent about preventing harassment and discrimination. Therefore any offensive remarks about race, religion age or sexual orientation should be banned. In fact policies should be clearly explain that managers will not tolerate intimidating or harassing behavior, or anything that interferes with workplace productivity (Ajzen,1991). Manager should inform employees, and then trust them to do the right thing. Exercising a certain amount of control is appropriate, but you also need to be reasonable and allow employees to engage with one another.

\subsubsection{To Whom Provide A Margin of Freedom}

Many managers are having more trust on talented employees and give them the ability to choose they have to work, as well as how when and where they have to perform. This is actually one of the core elements of a fulfilling career, (Kleanthis et al, 2014)

Managers should be able to select the right remote communication tools in order to communicate and work together easily. Adopting high-freedom policies is a competitive advantage in the talent market. The more nuanced and relevant policies are, the more competitive hiring brand will be. If the managers have great benefits but don't have a dedicated (and concise) section of careers page or job descriptions that explain or don't talk about the freedom during candidate interviews, managers are missing an opportunity to leverage that asset. It's much easier to recruit and retain great talent when managers are giving employees what they want while helping them excel at their jobs. More and more people want the freedom to decide where, when, how, and with whom they work.

\subsubsection{Freedom in the Place of the Work}

Few companies are letting the work done remotely, from-home or they let their employees choose their manager and their work, select their own professional development opportunities they can also provide incentive based compensation for good performance, employee can get security ownership plan to let the employee feel as an one of the owners of the company and became more responsible, (Lau et al, 2002). Managers should be aware of how they can balance the Work/life of everyone in the organization so they have to be good listener and understand how to make how work as easy as possible for them according to them more freedom and flexibility to be able to solve this dilemma (Faye et al,2014). 


\subsection{Employee Reactions to the Freedom}

Some employees are just not interested, while some employee get jazzed about having the ability to really express who they are, others have little interest in it. In fact, autonomy is no different. Some people love to have the leeway to make important decisions on their own. But others operate better in an environment in which their boundaries are well defined. That is why many employees are more enjoyed when their manager yells at them, constantly telling them what to do and how to do it. It makes them want to work harder. Managers should understand that there will always be people who love the idea of having a more open expressive setting. But there will also always be those who do not have much interest in it. Thus, the leeway of freedom depends on the culture, but changes should be introduced slowly over time. Before asking for employee input on the company's strategic plan, managers should consider the following: Not all cultures are ready to become more progressive overnight. Therefore, it is up to the manager to be sure to thoroughly evaluate the impact more freedom will have on the employees' productivity, job satisfaction and creativity, (Steiner,2017).

\section{Methodology}

This section presents the methods and procedures used for this study including the research design, the respondents of the study, research instrument, validation of the instrument, data gathering procedure, scoring procedure and the statistical treatment of data.

\subsection{Research Design}

Research design plays a vital role in defining the overall strategy that is being used within the research. Moreover, research design also allows the research to plan the activities of the research, which includes data analysis. In order to acquire the predefined aim of the study, researcher has used the descriptive scheme and carried out a questionnaire survey.

Thus, this study made use of the exploratory method through survey addressed randomly to 10 employees of top 5 Companies in Bahrain in 2018.

\subsection{Respondents of the Study}

The respondents of the study were employees from 5 companies taken from the list of top companies in the Kingdom of Bahrain in $2018^{3}$. The sample size of the study is presented in the following table

\footnotetext{
${ }^{3}$ Source:

https://gulfbusiness.com/revealed-top-10-companies-bahrain-2018/
} 
Table 1: Companies profile

\begin{tabular}{|l|l|l|l|}
\hline & \multicolumn{1}{|c|}{ Activity sector } & \multicolumn{1}{|c|}{$\begin{array}{c}\text { Market } \\
\text { capitalization }\end{array}$} & $\begin{array}{c}\text { Total sample size: 50 } \\
\text { Employees }\end{array}$ \\
\hline Ahli United Bank. & $\begin{array}{l}\text { Banking and } \\
\text { Financial Services }\end{array}$ & $\$ 5.34 \mathrm{bn}$ & 10 \\
\hline Aluminium Bahrain. & Mineral Resources & $\$ 2.39 \mathrm{bn}$ & 10 \\
\hline $\begin{array}{l}\text { National Bank } \\
\text { of Bahrain. }\end{array}$ & $\begin{array}{l}\text { Banking and } \\
\text { Financial Services }\end{array}$ & $\$ 2.21 \mathrm{bn}$ & 10 \\
\hline GFH Financial Group. & $\begin{array}{l}\text { Banking and } \\
\text { Financial Services }\end{array}$ & $\$ 1.42 \mathrm{bn}$ & 10 \\
\hline BBK & $\begin{array}{l}\text { Banking and } \\
\text { Financial Services }\end{array}$ & $\$ 1.26 \mathrm{bn}$ & 10 \\
\hline
\end{tabular}

So, the target distribution of the respondents of the study is represented as follows:

Table 2: Sample of respondents distribution

\begin{tabular}{|l|l|}
\hline Numbers of companies & Employees \\
\hline 5 & 50 \\
\hline
\end{tabular}

As we can see that four company of five are in the Banking sector which represent $80 \%$ of the sample.

\subsection{Research Instrument}

The instrument used in this research is questionnaire which is basically a quantitative method to conduct an analysis. The motivation to choose this sample of Companies is that they are listed under the top largest companies in Bahrain so their degree of visibility and how it can influence the employees' perceptions regarding the autonomy policies undertaken by those companies is expected to be more plausible (Martins et al, 2012).

This method of investigation was employed to gather and analyze data related to employees' perceptions regarding the autonomy policies undertaken by these companies.

So, we are expecting getting significant relationship between the autonomy policies of these Corporations and positive employees' perceptions.

In this study, this approach provides the opportunity to assess the significant influence of the autonomy on employees' perceptions using a structured, written survey.

First, we collected data through the answers of our respondents. Then, the qualitative data will be analyzed to help explain, or elaborate the quantitative results obtained in the first phase. This sequential method provides statistical explanation of the research problem and understanding of the phenomena by exploring respondents' views in depth based on the quantitative results. 
The research covers Five Companies in the Kingdom of Bahrain. The data to be used in this study comes from survey questionnaire with a sample size of 50 employees using a non-probabilistic sampling. Each company was been given10 questionnaires to answer.

Part I of the questionnaire deals with profile of the Company as described in the table below:

Table 3: Respondent Profile

\begin{tabular}{|l|l|l|}
\hline gender & Years of experience & qualifications \\
\hline
\end{tabular}

Part II of the questionnaire determines the employees' perceptions regarding the autonomy initiatives undertaken by the companies in the Kingdom of Bahrain. The items will be rated using a 5-point Likert scale ranging from:

\section{1-Strongly Disagree 2- Disagree 3-Neither agree or disagree 4- Agree 5-Strongly Agree}

In this part of study we distinguish the employees' perceptions using the following questions:

Table 4: Employees' perceptions of autonomy initiatives

\begin{tabular}{|l|}
\hline Autonomy initiatives \\
\hline Autonomy of manager leadership and control \\
\hline Managers in our company encourage the initiatives taken by the employees \\
\hline In our company if mistakes are done managers are not shouting and calm down, \\
\hline In our company we are not working in fear. \\
\hline Managers are building trust with us. \\
\hline Manager are explaining the importance of the assigned tasks \\
\hline Autonomy in Methods, resources \\
\hline Our managers give us the choice without any boundaries \\
\hline Our managers give us the choice with clear boundaries \\
\hline Managers are providing Training, technology, to reach the organizational goals \\
\hline Managers are getting out of the way and let us do our job \\
\hline $\begin{array}{l}\text { Managers are providing us what we need to do our jobs well and they are providing tools to } \\
\text { reach goals }\end{array}$ \\
\hline Our employees are encouraging us to take risks, try new ideas and innovate. \\
\hline Managers assigned to us method of work \\
\hline managers assigned to us goals \\
\hline Leeway in speeches, places and schedules \\
\hline Managers let us to make decisions about more peripheral aspects of the task, \\
\hline Managers are providing us flexible schedule \\
\hline Managers discuss with us our problem and get us leeway in our speech \\
\hline Managers let us doing the work anywhere \\
\hline Managers let talented people perform freely \\
\hline
\end{tabular}


Part III of the questionnaire determines

Table 5: The reactions of employees regarding the importance of the autonomy initiatives

\begin{tabular}{|l|}
\hline Autonomy initiatives \\
\hline Freedom to work anywhere let us being motivated \\
\hline Freedom to work with flexible schedule let us being motivated \\
\hline Freedom to work without boundaries let us motivated \\
\hline Freedom to get the resources, methods and tools let us motivated \\
\hline
\end{tabular}

\subsection{Data Gathering Procedure}

The researcher undertakes the following steps

1) A questionnaire was prepared according to the study objectives

2) Distribution of the questionnaire was undertaken be the researcher to the respondent Directions on how to till the questionnaire were clearly stated in the questionnaire, so as to let them know the significance of the study and the instructions required to complete the questionnaire, finally the data sourced were processed, presented, analyzed and interpreted to arrive at specific findings, conclusion and recommendations.

\subsection{Data processing and Statistical Treatment of Data}

The researcher uses the following statistical tools to analyze the data.

1) Frequency distribution: this is used to organize the number of responses of the subjects of the study in the different items in the instrument in Tabular or graphical form for clarity and understanding of data gathered

2) Percentage: this is used to determine the magnitude of the number of responses for a particular item in the instrument in relation to the total responses

In this study, this was used to determine the significant relationship between autonomy initiatives and Employees perceptions.

\section{Findings}

\subsection{Respondent Profile}

Table 6: Respondent Profile

\begin{tabular}{|l|l|l|l|l|l|l|}
\hline & Gender & \multicolumn{2}{|c|}{$\begin{array}{c}\text { Mean of Years of } \\
\text { experience }\end{array}$} & \multirow{2}{*}{$\begin{array}{c}\text { No } \\
\text { qualifications }\end{array}$} & \multicolumn{3}{|c|}{ Qualifications } \\
\cline { 6 - 8 } & & & Bachelor & Master & PhD \\
\hline Female & 19 & 3.17 & 5 & 12 & 2 & 0 \\
\hline Male & 31 & 5.22 & 10 & 19 & 1 & 1 \\
\hline Total & 50 & & 15 & 31 & 3 & 1 \\
\hline Percentage & 100 & & $30 \%$ & $62 \%$ & $6 \%$ & $2 \%$ \\
\hline
\end{tabular}

According the above table, $70 \%$ of our population is qualified. The majority are having (almost $62 \%$ ) bachelor degree. However, $30 \%$ were been recruited without a high degree but were studding or are actually studding in universities in Bahrain. 
We mentioned in our above development that the control it depends essentially on the qualifications and the experience of the employees. So it is not obvious that who is having a higher degree his performance will be excellent, it depends on others factors especially the experience years and on his own talent and he is performing in his workplace and if he was able to get the trust of his superior than he can be less controlled. Nonetheless, it seems that females' human resources are less than the males' employees. Generally, females need more assistance in their work because of their nature stress between the work and home responsibilities and may be they can be more subjected to do errors. But after getting sufficient experiences they may show a better performance than the males. All of these given developments are concluded from the observations of the general performance of many males and female staffs in many local companies in Bahrain. Therefore the control that will be exerted depends on the level of experiences, qualifications and talents, importance of the tasks, sector of activity, organizational goals, and especially on the leadership style of the managers in places. These directions can be developed in future researches.

In the next part, as our objectives in this study is to show how employees do perceive the autonomy given in their workplaces, we represent our results in the table as follows:

\subsection{Employees' perceptions of autonomy initiatives}

Table 7: Employees' perceptions of autonomy initiatives

\begin{tabular}{|l|l|l|l|l|l|}
\hline \multicolumn{1}{|c|}{ Autonomy initiatives } & \multicolumn{1}{|c|}{$\begin{array}{c}\text { Strongly } \\
\text { disagree }\end{array}$} & Disagree & \multicolumn{1}{|c|}{$\begin{array}{c}\text { Neither } \\
\text { agree or } \\
\text { disagree }\end{array}$} & Agree & $\begin{array}{c}\text { Strongly } \\
\text { agree }\end{array}$ \\
\hline Autonomy of manager leadership and control & 11 & 10 & 12 & 8 & 9 \\
\hline $\begin{array}{l}\text { Managers in our company } \\
\text { encourage the initiatives taken } \\
\text { by the employees }\end{array}$ & \multicolumn{1}{|c|}{11} & 9 & 13 & 2 \\
\hline $\begin{array}{l}\text { In our company if mistakes are } \\
\text { done managers are not } \\
\text { shouting and calm down, }\end{array}$ & 15 & 4 & 6 & 18 & 20 \\
\hline $\begin{array}{l}\text { In our company we are not } \\
\text { working in fear. }\end{array}$ & 2 & 10 & 15 & 15 & 5 \\
\hline $\begin{array}{l}\text { Managers are building trust } \\
\text { with us. }\end{array}$ & 5 & 6 & 5 & 23 & 12 \\
\hline $\begin{array}{l}\text { Managers are explaining the } \\
\text { importance of the assigned } \\
\text { tasks }\end{array}$ & 4 & & & & \\
\hline
\end{tabular}




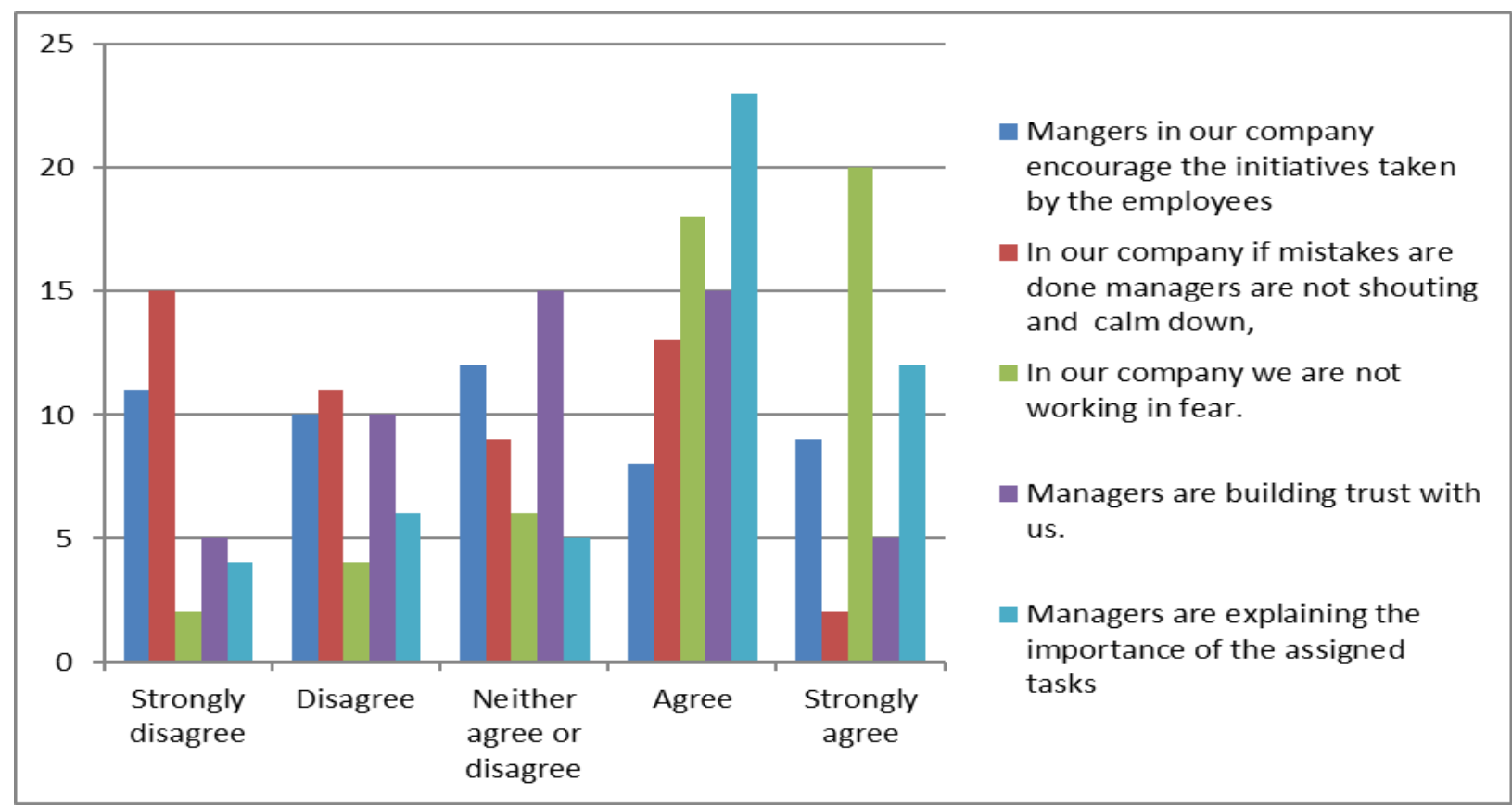

Figure 1: distribution of employees perceptions regarding the autonomy of manager leadership and control

Upon to the above distribution, it is clear that managers are more insisting on explaining the importance of tasks assigned to their employees in order to avoid errors or mistakes that is why we noticed that many employees are confirming that managers are very worried about errors occurrence and can even shouting in that cases. However, majority of employees they are agreeing that they are not working in fear and this can let them more comfortable and more involved in the achievement of organization goals. Especially of managers are building trust with them they will be for sure more motivated and responsible.

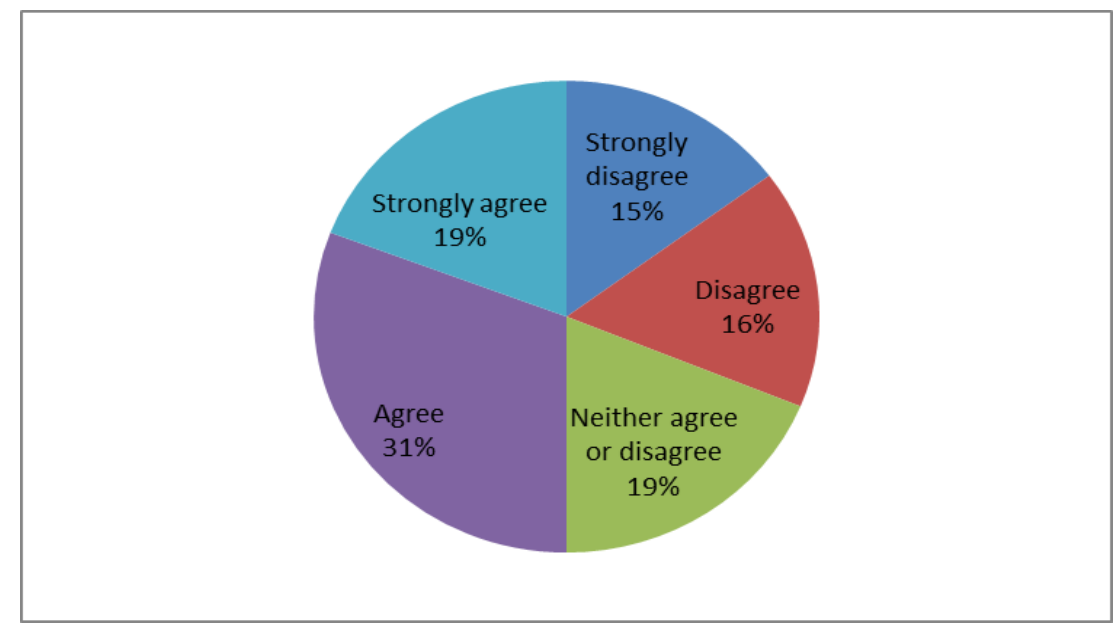

Figure 2: The employees perceptions repartition

This distribution can show that about $50 \%$ of the employees are agreeing a good leadership and acceptable control exerted by their managers. So as mush managers are related to their employees as much they have to be far enough ahead to motivate them. 


\begin{tabular}{|l|l|l|l|l|l|}
\hline \multicolumn{5}{|c|}{ Autonomy in Methods, resource, Choices } \\
\hline $\begin{array}{l}\text { Managers are providing us what we need to do our jobs well and they } \\
\text { are providing tools to reach goals }\end{array}$ & 13 & 14 & 11 & 10 & 2 \\
\hline $\begin{array}{l}\text { Our managers are encouraging us to take risks, try new ideas and } \\
\text { innovate. }\end{array}$ & 16 & 13 & 8 & 9 & 4 \\
\hline Our managers give us the choice without any boundaries & 32 & 12 & 5 & 1 & 0 \\
\hline Our managers give us the choice with clear boundaries & 2 & 2 & 8 & 31 & 7 \\
\hline $\begin{array}{l}\text { Managers are providing Training, and technology to reach the } \\
\text { organizational goals }\end{array}$ & 2 & 3 & 1 & 33 & 11 \\
\hline Managers are getting out of the way and let us do our job & 16 & 17 & 10 & 7 & 0 \\
\hline managers assigned to us to fix the goals & 22 & 17 & 6 & 3 & 2 \\
\hline Managers assigned to us method of work & 10 & 8 & 3 & 18 & 11 \\
\hline
\end{tabular}

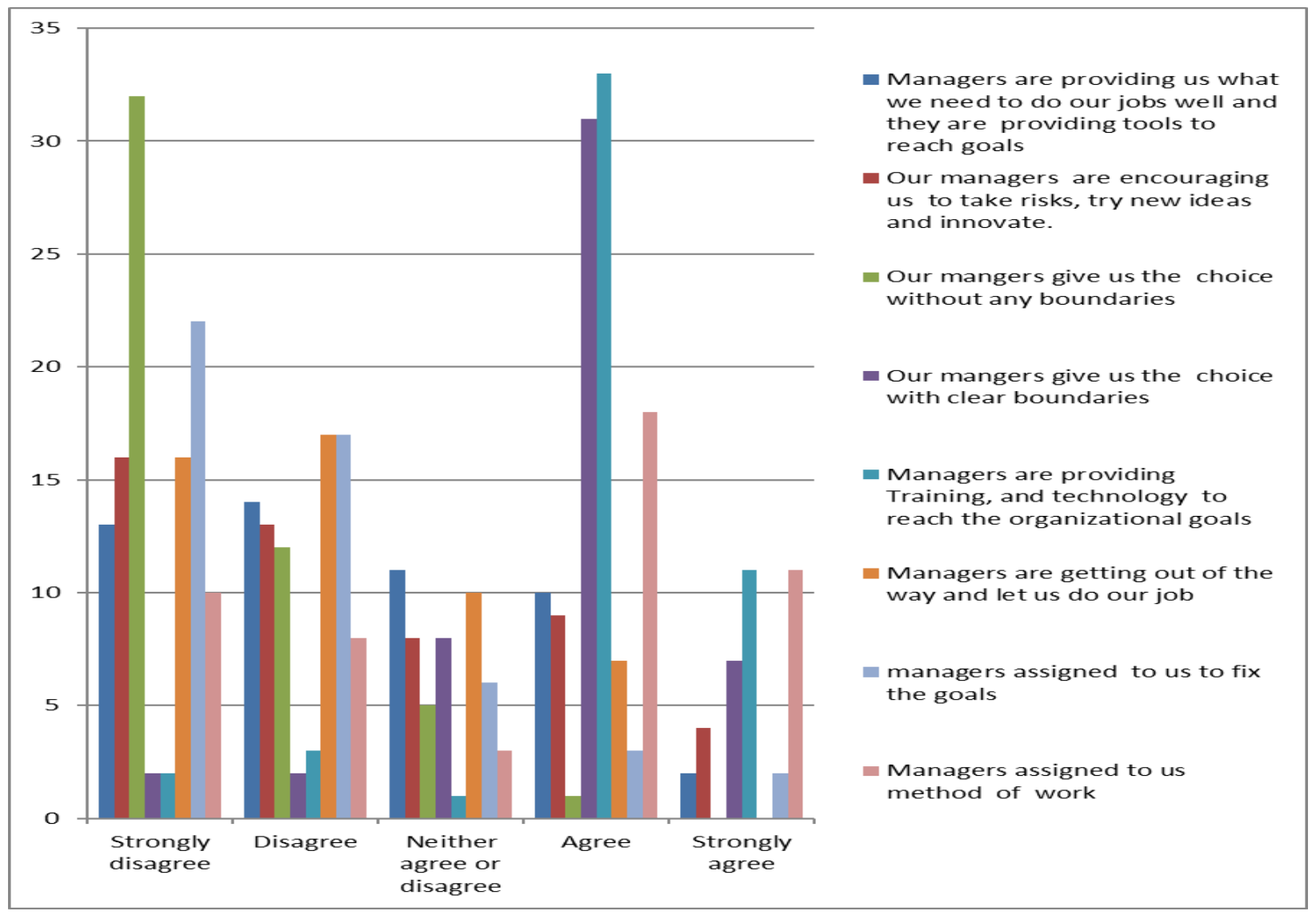

Figure 3: Autonomy in Methods, resource, Choices

Employees are agreeing in majority that their managers are giving them training and technology to reach goals. They are giving them the autonomy to make choices but with clear boundaries than they are assigned to them to choose the methods of how to do their work. However employees are disagreeing in majority that their managers are giving them choices without any boundaries and that is why they cannot choose their work goals and do not take the risks and try new ideas. Especially that the majority of the companies of our studies are operating in banking sector so that is why it is understood that managers they cannot accept mistakes and risks in their financial operations. 


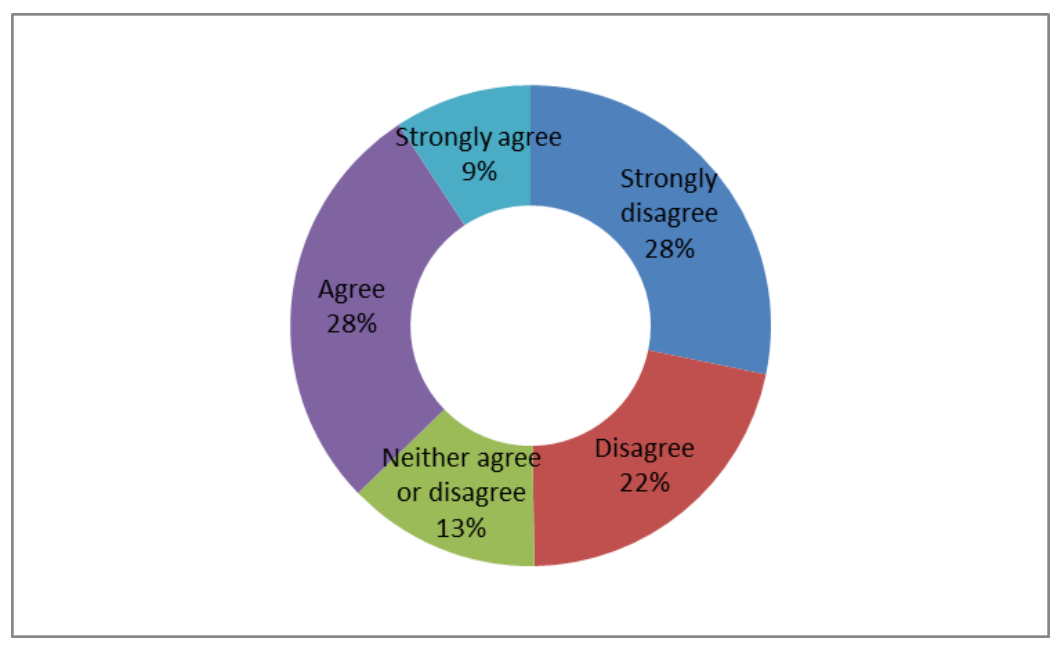

Figure 4: The employees perceptions reparation according to their perceptions of the autonomy in Methods, resource, Choices

Hers we can at the first glance get clear that the majority of employees (about 50\%) are disagreeing the autonomy of methods, choices and resources. Only $37 \%$ are agreeing that they can get such autonomy in their work place but in clear boundaries.

\begin{tabular}{|l|l|l|l|l|l|}
\hline \multicolumn{4}{|c|}{ Autonomy in speeches, places and schedules } \\
\hline $\begin{array}{l}\text { Managers let us make decisions about more peripheral aspects of the } \\
\text { task, }\end{array}$ & 3 & 5 & 2 & 17 & 23 \\
\hline Managers are providing us flexible schedule & 31 & 16 & 1 & 2 & 0 \\
\hline Managers discuss with us our problem and get us leeway in our speech & 2 & 7 & 10 & 18 & 13 \\
\hline Managers let us doing the work anywhere & 25 & 3 & 12 & 8 & 2 \\
\hline Managers let talented people perform freely & 11 & 8 & 10 & 12 & 9 \\
\hline
\end{tabular}

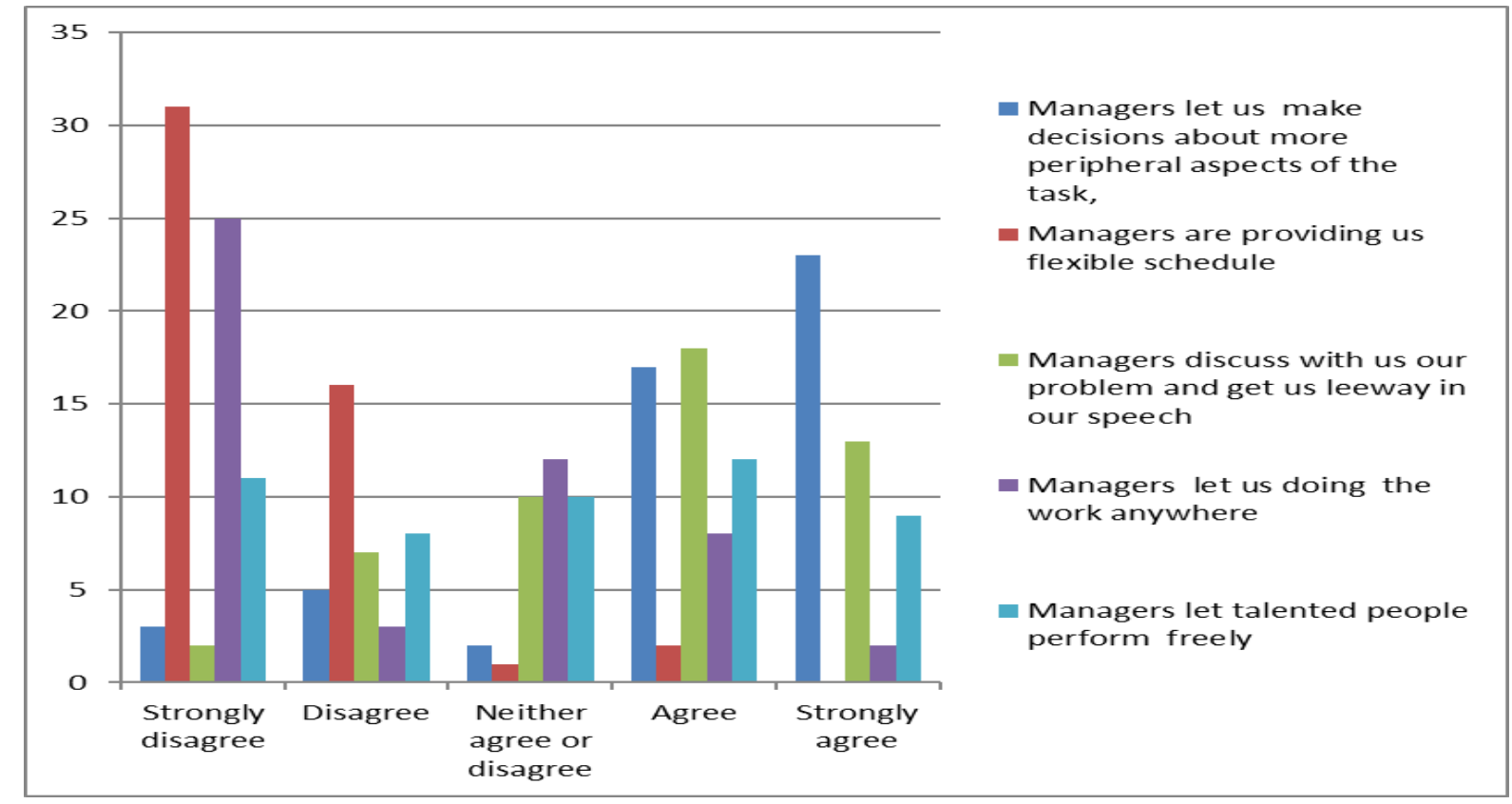

Figure 5: Autonomy in speeches, places and schedules 
It is very interesting to notice that the majority of employees are denying that their managers give them flexible schedule. Moreover, they are disagreeing that their managers are allowing them to do their work anywhere since it is very confidential work especially in the banking sector. Other important numbers of employees are also disagreeing that their managers can let talented peoples to perform freely.

This owing to the mentality of being scared of those who are very competent to show their selves and may be some managers are considering them as their future competitors and may be they will be promoted for their positions. So, under the fear of their competition they are ignoring the talented people and more worst they can exerted an excessive control on their performance.

However, managers can let employees take peripheral aspect of decisions, they can discuss with them and get them free to express their issues. In fact choice provides a sense of self determination even when choice is trivial or illusory

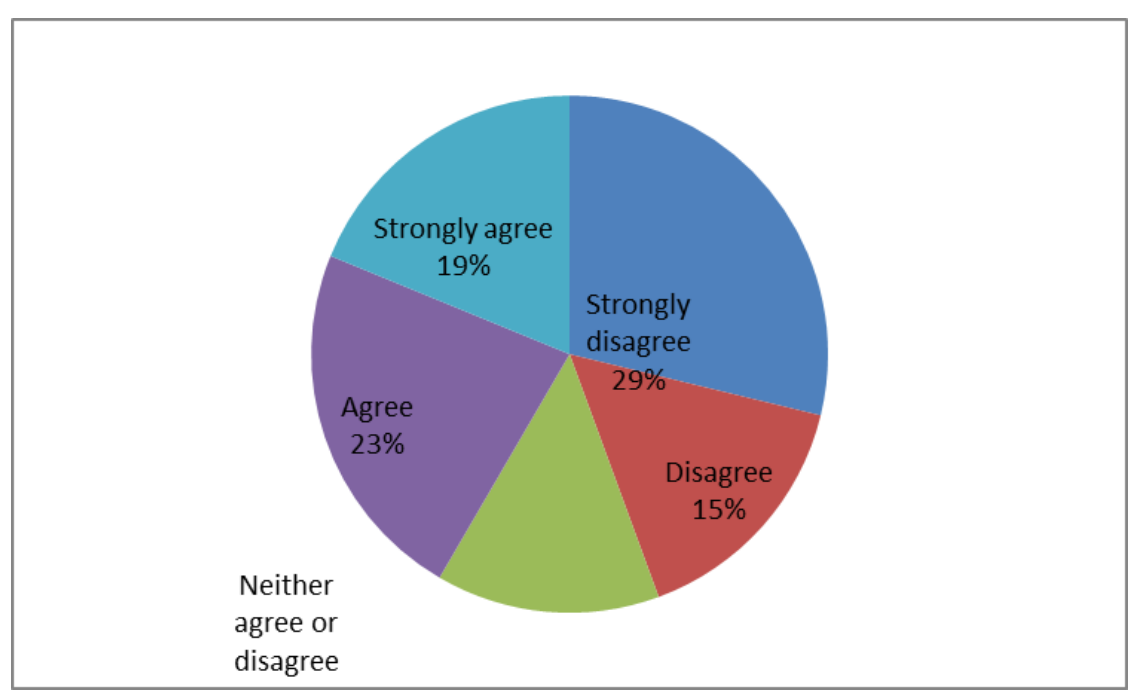

Figure 6: the employees perceptions repartition regarding the autonomy in speeches, places and schedules

Again we can notice a general disagreement, in concurrence of $45 \%$, of the autonomy in speeches, places and schedules. This is means that employees are only able to participate in peripheral decisions that is not related to strategic choices of places, times and goals.

\begin{tabular}{|l|l|l|l|l|l|}
\hline Total & 222 & 166 & 134 & 246 & 132 \\
\hline Percentage & 0.249438 & 0.186517 & 0.150562 & 0.276404 & 0.137079 \\
\hline
\end{tabular}




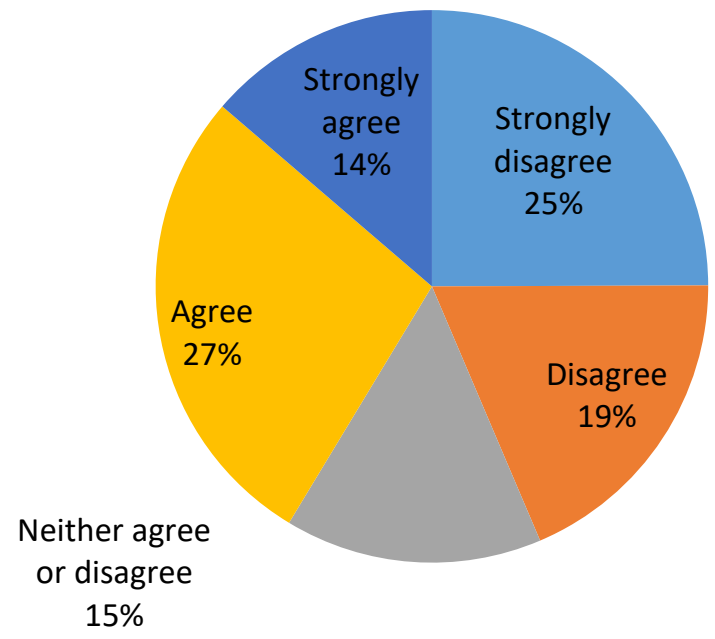

Figure 7: the overall reparation of employees perceptions regarding the autonomy initiatives

From the above distribution, it seems that about $40 \%$ of the population is agreeing that their managers are giving a leeway of freedom however $43 \%$ is disagreeing this pretention. So the majority is not considering that there is concrete freedom given by their managers and may be the $40 \%$ population is just giving us hypocrite answers under the fear of their bosses. Due to tow factors principals which are the organization culture may be not accepting such leeway value or the nature of activity in itself. Those company as we have mentioned, they are operating in banking sector that is why the managers are more practicing strict and tied control due to the nature of the banking transactions and they cannot get away and let employees do alone and take the risks , they cannot accept easily the mistakes in such types of calculations or financing affaires. This types of operations require a great attention and care and managers are following their employees in each step of the transaction so it is understood why we are getting a negative perception regarding the freedom given by the managers of those companies.

\subsection{The reactions of Employees Regarding the Importance of The Autonomy Initiatives}

Table 11: The reactions of employees regarding the importance of the autonomy initiatives

\begin{tabular}{|l|l|l|l|l|l|}
\hline \multicolumn{1}{|c|}{ Autonomy initiatives } & $\begin{array}{l}\text { Strongly } \\
\text { disagree }\end{array}$ & Disagree & $\begin{array}{c}\text { Neither } \\
\text { agree or } \\
\text { disagree }\end{array}$ & Agree & $\begin{array}{c}\text { Strongly } \\
\text { agree }\end{array}$ \\
\hline $\begin{array}{l}\text { Freedom to work } \\
\text { anywhere let us being } \\
\text { motivated }\end{array}$ & 0 & 0 & 0 & 42 & 8 \\
\hline $\begin{array}{l}\text { Freedom to work with } \\
\text { flexible schedule let us } \\
\text { being motivated }\end{array}$ & 0 & 0 & 0 & 12 & 38 \\
\hline $\begin{array}{l}\text { Freedom to work without } \\
\text { boundaries let us } \\
\text { motivated }\end{array}$ & 0 & 0 & 0 & 2 & 48 \\
\hline
\end{tabular}




\begin{tabular}{|c|c|c|c|c|c|c|}
\hline $\begin{array}{l}\text { Freedom to get the } \\
\text { resources, methods and } \\
\text { tools let us motivated }\end{array}$ & 0 & 2 & 0 & 13 & 35 & \\
\hline Total & 0 & 2 & 0 & 69 & 129 & 200 \\
\hline Percentage & 0 & 0.01 & 0 & 34.5 & 64.5 & 100 \\
\hline
\end{tabular}

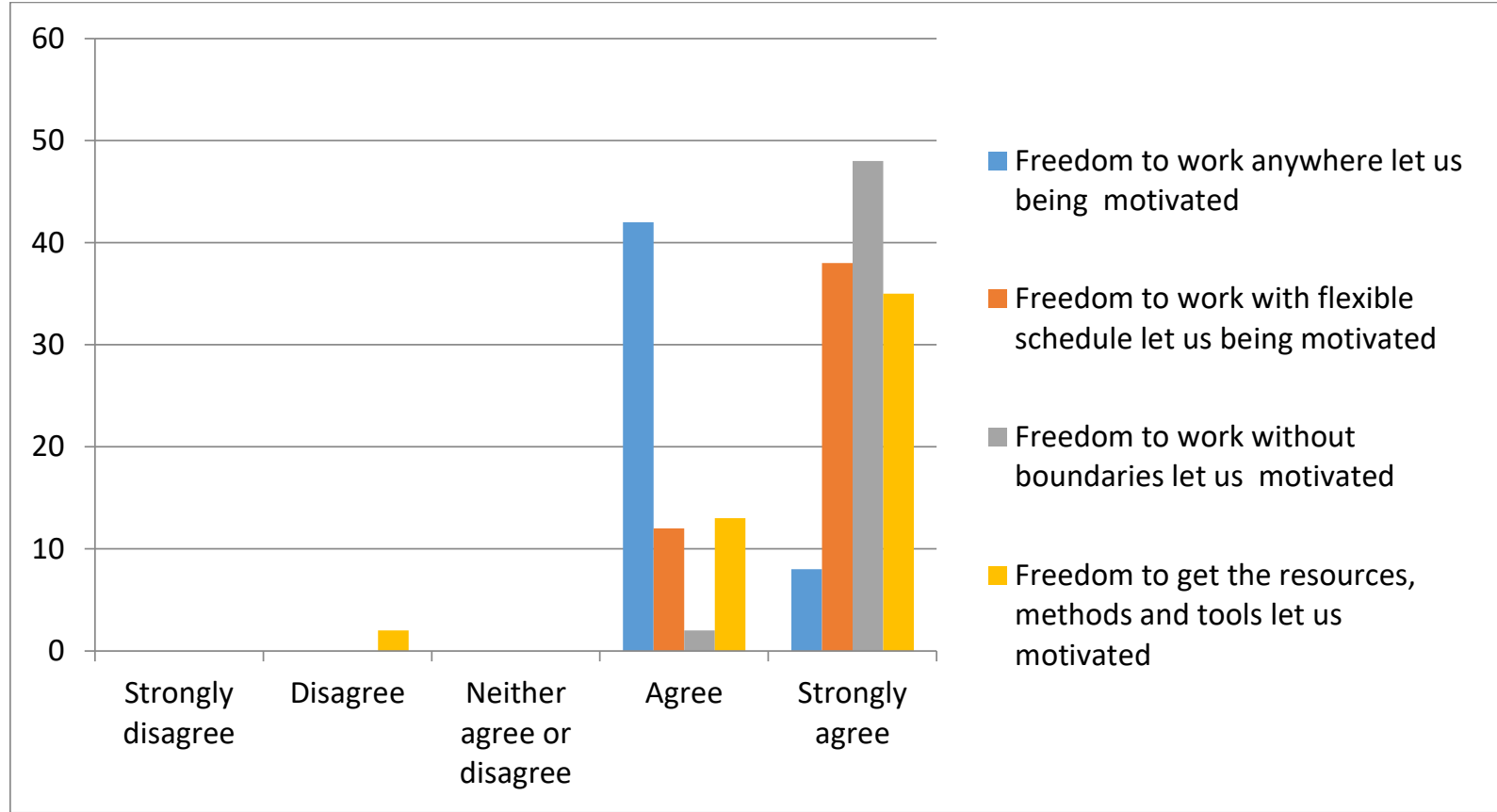

Figure 8: Employees' reactions regarding the importance of the autonomy initiatives

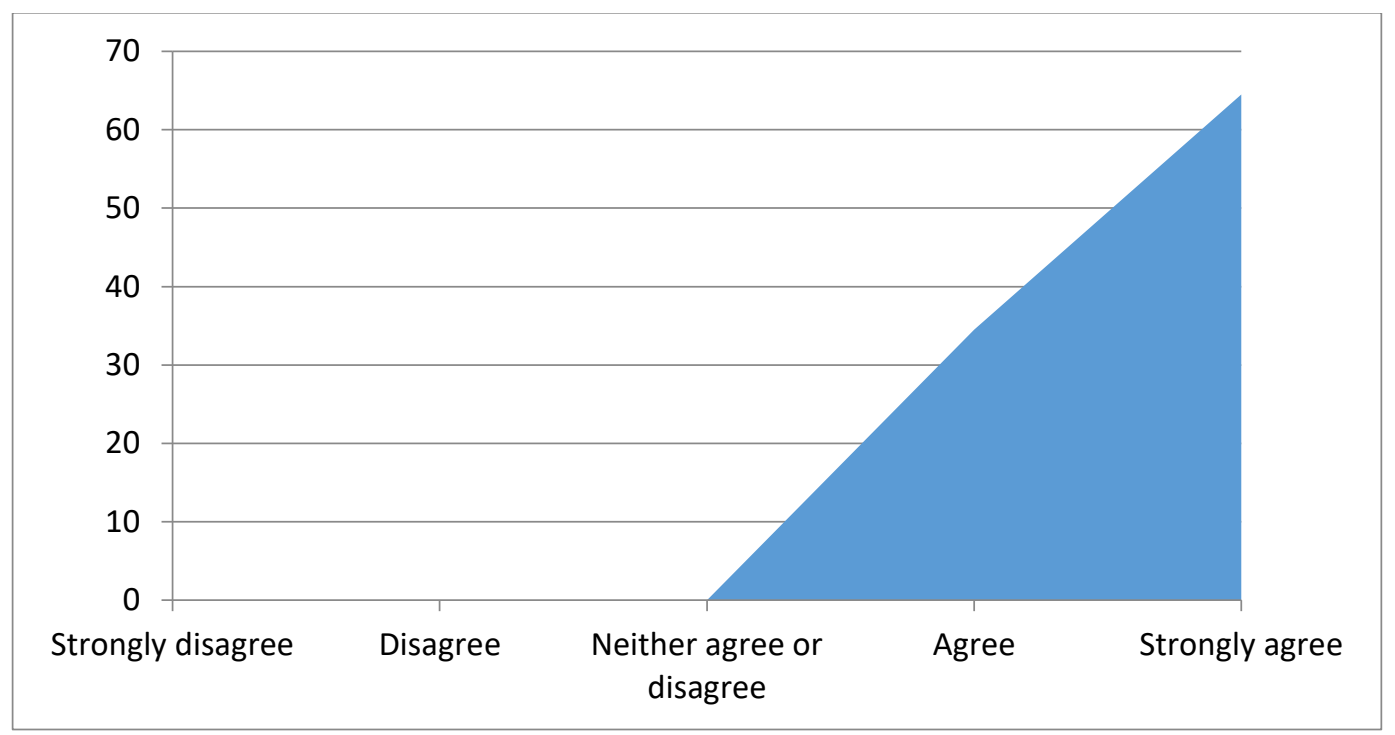

Figure 9: The overall distribution of employees reactions regarding the importance of the autnomy initiatives

$99 \%$ of the population is agree with the importance of the freedom in the work place and how it can motivate the employees to do their bets and reach the organizational goals effectively and 
efficiently. This is corroborate the human nature which is very aligned to the freedom desire and what this leeway can beneficiate the corporation in terms of productivity with more motivation and per consequence more effectiveness since the employees became more involved in the achievement of the predefined goals whenever the managers let them choose the methods, the resource the schedules, and focus only on the quality of their outputs.

\section{Conclusion and Recommendations}

In fact autonomy is one of the essential elements in building true employee engagement. Without it the workforce may become the land of the working dead, roaming endlessly in zombie like fashion, waiting to be told what to do nest. Not an enjoyable workplace neither for employees nor managers by any stretch. However in our study we conclude upon to our statistics that there is a general disagreement of the autonomy in its different dimensions and only managers are providing peripheral aspects of autonomy.

In fact, the level of autonomy depends essentially on the sector of activity and on leadership style and on the culture promoted in the organization. Since we are conducting our study on almost banking companies so that is why the level was moderated and not so important due to the confidentiality and accuracy of the operations in such companies.

Nonetheless the employees will be more motivated if managers let them performing in autonomy. Giving your staff the freedom to make highly strategic decisions is a great idea but this freedom should be given slowly over time.

In fact, there are many ways to encourage autonomy with the employees: If mistakes are done managers should just calm down. Because the fact that some managers are destructively critical when mistakes are made which can kill initiatives and consequently, employee engagement. If organizations aim to grow, it is essential they be full of people engaged with initiative. This doesn't come when employees work in fear.

We have also to hire autonomous people who can naturally engage. Managers should provide them what they need to do their jobs well, and then get out of the way. Doing so encourages employees to take risks, try new ideas and innovate. Managers should also be able to build trust with their employees. Without trust autonomy is impossible. However, when trust is present it sends employees the message that they are in command of their time, effort and reward and this trust should be mutual. The freedom of choice is also a key element to autonomy but too much choice can be detrimental that is why those who think autonomy means there are no boundaries are in error. So the managers should always keep the system to hold people accountable for results within clear boundaries people are empowered to determine how they will accomplish the tasks they are given. And more explicitly employees should be granted ownership. For instance, let the new employee to apply his recently learned technology skills and take the initiative, the project moved from a company must-do in the employee mind to this is an opportunity for him to use what he learned to benefit thousands of employees and what it has this new system has effect in terms of cost saving of several million dollars, so he is the initiator and not the company has to do such change. Also manager should provide tools to reach goals. 
Give to the employees the tools and resources they need to reach the organizational goals and theirs. Training, technology. Now, get out of the way and let people do their thing. If you hire people who want to give 110 percent and put them in an 85 percent environment, you'll do your organization greater harm than by hiring 85 percent in the first place. Don't grant autonomy if you as a manager aren't prepared to follow through. Keep in mind, taking away autonomy once you've granted it is a surefire employee engagement killer. when employees are intrinsically motivated they enjoy what they are doing more and find it more interesting they feel more creative and process information more deeply they persist more in the face of difficulty. They perform better, so intrinsic motivation is awesome in its power to get and keep us going.

The feeling of choice can be created fairly. the employees fist of all they have to understand why the goal they have been assigned has value, managers too often tell their employees what they need to do without taking time to explain why it is important and they suppose that the why is as obvious to the employees. When the goal is predetermined by management, employees should be allowed to decide how they will reach the goal and this can create the feeling of choice, allowing them to tailor their approach to their preferences and abilities which can increase their motivation toward their performance effectively, at least manager should provide the employees options for how to proceed. If managers have to assign both the goal and the method for reaching it, they have to try to create the feeling of choice by inviting the employees to make decisions about more peripheral aspects of the task, for instance if the employees have to attend weekly team meetings to improve communication and collaboration, managers can have team members take turns deciding what the topic of the meeting will be each week or even what kind of lunch will be ordered in. These more peripheral decisions create a feeling of choice even if they are not so meaningful or relevant to the goal itself.

\section{References}

[1] Ajzen, I. (1991). The theory of planned behavior. Organizational behavior and human decision processes, 50(2), 179-211.

[2] Al-Tit, A \& Suifan, T. S. (2015). The Mediating Role of Job Characteristics in the Relationship between Organizational Commitment and Job Satisfaction. International Journal of Business and Management, 10(9), 215-222. http://dx.doi.org/10.5539/ijbm.v10n9p215.

[3] Falkenburg, K., \& Schyns, B. (2007). Work satisfaction, organizational commitment and withdrawal behaviours. Management Research News, 30(10), 708-723. DOI 10.1108/01409170710823430.

[4] Faye, K., \& Long, Y. (2014). The impact of job satisfaction in the relationships between workplace politics and work related outcomes and attitudes: evidence from organizations in Senegal. International Journal of Business and Management, 9(5), 160-168. doi:10.5539/ijbm.v9n5p160.

[5] Fu, W., \& Deshpande, S. P. (2014). The impact of caring climate, job satisfaction, and organizational commitment on job performance of employees in a China's insurance company. Journal of Business Ethics, 124 (2), 339-349. DOI 10.1007/s10551-013-1876-y.

[6] Greasley, Kay, Bryman Alan , Andrew Dainty, Andrew Price, Robby Soetanto, Nicola King, (2005) "Employee perceptions of empowerment", Employee Relations, Vol. 27 Issue: 4, pp.354368, https://doi.org/10.1108/01425450510605697

[7] Hall, D. T., \& Schneider, B. (1972). Correlates of organizational identification as a function of career pattern and organizational type. Administrative Science Quarterly, 17(3), 340-350. 
[8] Hardiyana, Aan \& Yusup, Maulana \& Sidharta, Iwan, (2015). 'Perception of Work and Commitment toward Employee Satisfaction on Non-Ministerial Government Agencies in Bandung Indonesia. MPRA Paper No. 77075,

[9] Jiang, J. Y., Sun, L. Y., \& Law, K. S. (2011). Job satisfaction and organization structure as moderators of the effects of empowerment on organizational citizenship behavior: A selfconsistency and social exchange perspective. International Journal of Management, 28(3), 675693.

[10] Joo, B. K., \& Park, S. (2010). Career satisfaction, organizational commitment, and turnover intention: The effects of goal orientation, organizational learning culture and developmental feedback. Leadership \& Organization Development Journal, 31(6), 482- 500. DOI $10.1108 / 01437731011069999$.

[11] Kleanthis K. Katsaros \& Athanasios Tsirikas (2014), Exploring employees' perceptions, job-related attitudes and characteristics during a planned organizational change, International Journal of Business Science and Applied Management 9(1):36-50

[12] Lau, C. M., David, K. T., \& Zhou, N. (2002). Institutional forces and organizational culture in China: Effects on change schemas, firm commitment and job satisfaction. Journal of International Business Studies, 33(3), 533-550.

[13] Li Tao,; Corrine Wu; Yat-Hung Chiang ; Francis Kwan-Wah Wong,(1970).Generational Perceptions of Freedom-Related Work Values: Hong Kong's Implementation of a No-SaturdaySite-Work Policy in Construction, Advances in Experimental Social Psychology, Volume 5, Pages 187-248

[14] Martins, H., \& Proença, T. (2012). Minnesota Satisfaction Questionnaire-Psychometric properties and validation in a population of Portuguese hospital workers. FEP Journal- Economics \& Management: Working Paper, 471,1-20.

[15] Steiner, Ivan D., (2017). Perceived Freedom. Vol. 143, Issue 7 (July 2017)

[16] Whaley, Sherrle R. \& Henderson, Janet L. (1994). The Creative Work Environment: Manager and Employee Perceptions of Factors that Influence Creativity Within Land. Grant Communication Units, Journal of Applied Communications, Vol. 78, Iss. 3. https://doi.org/10.4148/10510834.1409

[17] Won-Moo Hur\& Tae-Won Moon \&Sung-Hoon Ko, (2018). How Employees' Perceptions of CSR Increase Employee Creativity: Mediating Mechanisms of Compassion at Work and Intrinsic Motivation'J ournal of Business Ethics,, Volume 153, Issue 3, pp 629-644

*Corresponding author.

E-mail address: bouguilasihem@ yahoo.fr 